\title{
Radiography for head trauma in children: what guidelines should we use?
}

\author{
S Moreea, S Jones, $\mathrm{N}$ Zoltie
}

\begin{abstract}
Objective - To audit the appropriateness of skull radiography in children attending an accident and emergency (A\&E) department with head injuries.

Methods - 569 children presenting to a large teaching hospital A\&E unit were retrospectively audited. The indications for radiography according to British published guidelines and American published guidelines were compared with the actual requests for radiography. The criteria for admission from the two guidelines were also compared with the actual admissions. Results - 50\% of children presenting with head injury actually had skull radiography. If British guidelines for the use of skull radiography had been complied with, $63 \%$ of children should have had radiography, but if American guidelines had been used, $18 \%$ would have required radiography. All the actual fractures identified were in this $18 \%$.

Conclusions - The British guidelines overinvestigate children with head injury. This seems to have been recognised clinically, and the doctors did not adhere to the guidelines. Neither did they adhere to the American guidelines, which would have resulted in a further reduction in radiography. All the fractures identified were covered by the American guidelines. The American guidelines for skull radiography can be safely used in a British A\&E unit. ( $¥$ Accid Emerg Med 1997;14:13-15)
\end{abstract}

Keywords: head injuries; children; indications for skull radiography

Head injury is a common complaint in the accident and emergency (A\&E) department, and almost half of the attenders are children. ${ }^{1}$ The correct management of head injuries in children remains a worrying problem for junior doctors in $\mathrm{A} \& \mathrm{E}$, and they often turn to guidelines for reassurance. Guidelines have in the past been published in Britain for the management of head trauma in adults ${ }^{2}$ and they have been found to apply equally well to children. ${ }^{3}$ These guidelines have not changed in the past 10 years and are summarised in table 1 . The American guidelines for the management of head trauma are different: patients with scalp laceration, haematoma, contusion, and abrasion but without any neurological deficit are not candidates for skull radiographs. ${ }^{4}$ They are considered to be low risk patients in whom intracranial injuries are extremely rare.
Admission following head injury also differs between the two guidelines, but is not quite so contradictory. Thus the British guidelines suggest admission for patients with a skull fracture, confusion, or neurological symptoms or signs at the time of examination, difficulty in assessing the patient, and lack of a responsible adult to supervise the patient. ${ }^{2}$ The American criteria indicate that patients who present after head trauma with focal neurological signs, penetrating injuries, and depressed levels of consciousness are high risk patients who require emergency computerised tomography (CT) and a neurosurgical review, skull radiography being of limited use in these cases.

The American management strategy has been shown to reduce the number of skull $x$ rays without missing intracranial injury. ${ }^{4}$ Now that most British hospitals have access to CT, implementation of the American guidelines for head trauma is theoretically feasible. We therefore reviewed the case notes of all children presenting to an A\&E department with a complaint of head trauma during three representative months to audit whether the British guidelines of management were followed, and then hypothetically applied the American guidelines for the same patients to determine the effect of a change in guidelines on the amount of skull radiography performed and whether use of these guidelines might have missed any intracranial injuries.

\section{Methods}

The case notes of all children less than 15 years old who attended the A\&E department during May, July, and October 1992 with a primary complaint or discharge diagnosis of head injury were retrieved and analysed. Based on patterns of children's injuries presenting over previous years, these three months were considered to be representative of the whole year. Patients presenting with multiple trauma including severe head injuries and patients referred directly to the neurosurgeons from other hospitals were not included in the study.

Each set of case notes was audited to determine whether the recommended British and American criteria for skull radiography were recorded and whether skull $x$ rays (Towne's view, posteroanterior, and both laterals) were requested. The number of radiographs showing a skull fracture was noted, all $x$ rays being formally reported by senior radiologists. The British criteria for admission were also audited and the number of admissions noted. The number of skull fractures which could have been missed using either set of guidelines was 
Table 1 Criteria for radiography

\begin{tabular}{ll}
\hline British criteria (for $x$ ray) & American criteria (for NO x ray) \\
\hline Loss of consciousness or amnesia at any time & Asymptomatic \\
Neurological symptoms and signs & Headache \\
Cerebrospinal fluid or blood from the nose or ear & Scalp laceration/contusion/abrasion/haematoma \\
Suspected penetrating injury & Dizziness \\
Scalp bruising or swelling & Absence of other risk criteria \\
\hline
\end{tabular}

determined, as well as the number of patients who would have been sent home using the American guidelines but who might later deteriorate.

No attempt was made to contact those patients who were sent home. However, review of hospital and $\mathrm{A} \& \mathrm{E}$ registers confirmed that no patient reattended as a result of a previous episode of head injury. We therefore assumed that those patients sent home had no significant complications.

\section{Results}

Five hundred and sixty nine patients presented over the study periods. Table 2 shows the numbers presenting in each age range studied: in a subset analysis of subsequent results there were no significant differences in radiography rates of admission rates between the age groups. The numbers were therefore amalgamated for presentation of results.

Table 3 shows the audit of radiography using the British criteria: 240 patients $(42 \%$ of all patients) correctly had radiographs, $113(20 \%$ of all patients) should have had radiography but did not, and 42 patients ( $7 \%$ of all patients) had radiographs without fulfilling the criteria.

Table 4 shows the audit of admissions using the British criteria:. 45 patients $(7.9 \%$ of all patients) were correctly admitted, four patients $(0.7 \%)$ were admitted despite guidelines indicated no necessity for admission, 13 patients ( $2.3 \%$ of all patients) were discharged despite guidelines indicating admission, and 507 (89\% of all patients) were correctly discharged.

Table 5 highlights the comparison between the theoretical use of the British guidelines, the actual use of radiography, and the theoretical use of the American guidelines. Seven skull fractures were actually detected: all seven were in the group defined by the American Guidelines as requiring radiography. Use of the American guidelines would thus have reduced the incidence of radiography from a theoretical $63 \%$ (with correct use of the British guidelines) down to $18 \%$, and included all the fractures identified.

The internal audit showed poor compliance with either set of guidelines, $50 \%$ of children actually having radiographs.

\section{Discussion}

The study revealed that if the British guidelines were followed, $63 \%$ of attenders required skull

Table 2 Number of patients presenting

\begin{tabular}{lllll}
\hline & May & fuly & October & Total \\
\hline 0-4 years & 145 & 97 & 92 & 334 \\
5-9 years & 36 & 66 & 40 & 142 \\
10-14 years & 34 & 27 & 32 & 93 \\
Total & 215 & 190 & 164 & 569 \\
\hline
\end{tabular}

Table 3 Audit of radiography using British guidelines

\begin{tabular}{llc}
\hline & $\begin{array}{l}\text { Guidelines indicate } \\
\text { radiography }\end{array}$ & $\begin{array}{l}\text { Guidelines indicate } \\
\text { no radiography }\end{array}$ \\
\hline Radiography & 240 & 42 \\
No radiography & 113 & 174 \\
\hline
\end{tabular}

Table 4 Audit of admissions using British guidelines

\begin{tabular}{llc}
\hline & $\begin{array}{l}\text { Guidelines indicate } \\
\text { admission }\end{array}$ & $\begin{array}{l}\text { Guidelines indicate } \\
\text { no admission }\end{array}$ \\
\hline Actually admitted & 240 & 42 \\
Discharged & 113 & 174
\end{tabular}

radiography, compared to about $18 \%$ using the American criteria. In practice, $50 \%$ of patients had skull radiography. Guidelines were not followed in $27 \%$ of patients: $20 \%$ had no radiography (without apparent clinical detriment) and $7 \%$ had unnecessary radiography. These findings are not surprising, as it has been shown that the constant use of guidelines is difficult to sustain and that their application needs regular monitoring if they are to be useful in clinical management. ${ }^{5}$ The most important finding, however, is that by following the American criteria only $18 \%$ of patients would have had radiographs, and these would have included all the fractures. We therefore recommend that there is no need for skull series in patients who present with scalp haematoma, laceration, or contusion-that is, we suggest that "scalp bruising or swelling" be removed from the list of British guidelines.

The exception to this recommendation lies in the American criteria, wherein children under 2 years of age are regarded as moderate risk, and radiography may be indicated. There were 90 patients under the age of 2 in our series, and we did not feel that this was a large enough group to audit specifically, since the incidence of fracture and complications was so low that large numbers would be needed to confirm or refute the validity of the guidelines.

Our results differ from other studies which have shown that the number of skull series could be reduced by between $37 \%$ and $51 \%$ if criteria for $x$ rays were followed. ${ }^{5}$ We found that our patients were underinvestigated. The explanation may lie in the fact that senior house officers were following their clinical judgement which would appear to be at odds with the British guidelines. Where clinicians consistently differ from guidelines then two alternatives exist. One alternative is that the guidelines are correct, and more education and training is necessary to encourage doctors to adhere to them. The second alternative is that the guidelines are not appropriate to current clinical practice, and clinical judgement must always be allowed to override. The indications from this study are that, judged by the American criteria, the junior doctors recognised that the British guidelines were no longer wholly

Table 5 Comparison of British guidelines with American guidelines, Values are number (\%) having radiography

$\begin{array}{ll}\text { British guidelines } & 352(63 \%) \\ \text { Actual number having radiographs } & 282(50 \%)\end{array}$

$\begin{array}{ll}\text { Actual number having radiographs } & 282(50 \%) \\ \text { American guidelines } & 105(18 \%)\end{array}$ 
appropriate, and used clinical judgement to reduce the number of radiographs requested, though not as few as the American guidelines would have indicated.

Guidelines for admission were also not followed accurately, but not to the same extent as with skull radiography. Only $2.3 \%$ of patients were inappropriately discharged but we have no evidence that they came to harm. More encouragingly, only $0.7 \%$ of patients were inappropriately admitted. Our rate of admission was $8.6 \%$ (theoretically $10.3 \%$ needed admission), compared to between 13 and $25 \%$ in other studies. ${ }^{67}$ It is therefore apparent that no substantial savings on resources would have been made if the guidelines for admission were adhered to completely.

It also becomes apparent that the use of guidelines demands constant reappraisal especially in $\mathrm{A} \& \mathrm{E}$ departments where junior staff changes every six months. The use of posters as a reminder of guidelines has been advocated and tried successfully in other departments. ${ }^{8}$

\section{CONCLUSIONS}

We conclude that the use of the British guidelines for skull radiography in children in our $A \& E$ department creates a large demand for radiography ( $63 \%$ of attenders). The use of the American guidelines appears to reduce the number of radiographs requested in children presenting with head injury, without apparent risk of missing significant injury or skull fracture. We therefore recommend the use of the American guidelines along with techniques for ensuring their uptake.

1 Brookes M, MacMillan R, Culley S, Anderson E, Murray S, Mendelow D, et al. Head injury in Accident \& emęrgency demiol Community Health 1990;44:147-51.

2 Briggs M, Clarke P, Crockard A, Cummins B, Galbraith S, Garfield G, et al. Guide lines for the initial management after head injury in adults. Suggestions from a group of after head injury in adults. Suggestion

3 Teasdale GM, Murray G, Anderson E, Mendelow AD, MacMillan R, Jennett $B$, et al. Risks of acute intracranial haematoma in children and adults: implications for managing head injuries. BMJ 1990;300:363-70.

4 Masters SJ, McClean PM, Acarese MS, Brown RB, Campbell JA, Freed HA, et al. Skull x-ray examinations after head trauma. Recommendations by a multidisciplinary panel and validation study. N Engl J Med 1987; 316:84-91.

5 Clarke JA, Adams JE. The application of clinical guidelines for skull radiography in the accident and emergency department: theory and practice. Clin Radiol 1990;41: 152-5.

6 Boulis ZF, Dick R. Head injuries in children-aetiology, symptoms, physical findings and X-ray wastage. Br J Radiol symptoms, physica

7 Miller JD. Changing patterns in acute management of head injury. J Neurol Sci 1991;103:33-7.

8 McNally E, de Lacey G, Lovell P, Welch T. Posters for accident departments: simple method of sustaining reduction in x-ray examinations. BMJ 1995;310:640-2.

The Annual meeting will be held in Oxford on 24-25 March 1997. There will be a session of free communications and symposia on aspects of the immunological response to trauma. For details, contact:

\author{
Dr R N Barton \\ North Western Injury Research Centre \\ Stopford Building \\ Oxford Road \\ Manchester M13 9PT \\ Tel: 0161275 5188; Fax 01612755190
}

